\title{
Proposta de diretrizes para elaboração de política de indexação em bibliotecas universitárias: um estudo sociocultural com protocolo verbal
}

\author{
Propuesta de directrices para la elaboración de la política de indización \\ en las bibliotecas universitarias: un estudio sociocultural con protocolo verbal \\ A proposal of guidelines for the development of an indexing policy in university libraries: \\ a verbal-protocol-based socio-cultural study
}

Paula Regina DaL'Evedove (1), Mariângela Spotti Lopes FuJita (2)

(1) Universidade Federal de São Carlos, Departamento de Ciência de Informação, Rodovia Washington Luís, Km 235, CEP.

13.565-905, São Carlos, SP, Brasil. Correio eletrônico: dalevedove@ufscar.br. (2) Universidade Estadual Paulista, Av. Hygino Muzzi Filho, 737, Campus Universitário, CEP. 17525900, Marília, SP, Brasil. Correio eletrônico: fujita@marilia.unesp.br

\begin{abstract}
Resumen
Se analiza la política de indización desde la perspectiva humana del tratamiento temático de la información, teniendo en cuenta las indicaciones y conceptos teóricos; detalles de la práctica de la profesión relacionada con la actividad de indización; y la realidad de las bibliotecas universitarias. Para ello, se aplicó la metodología del protocolo verbal en grupo a indizadores profesionales. Como resultado, se presentan ocho directrices para la elaboración de políticas de indización en las bibliotecas universitarias brasileñas.
\end{abstract}

Palabras clave: Tratamiento temático de la información. Políticas de indización. Aproximación sociocultural. Protocolo verbal. Bibliotecas universitarias. Brasil.

\section{Apontamentos iniciais}

Nos últimos anos houve um aumento significativo de pesquisas brasileiras sobre política de indexação, com destaque para os trabalhos apresentados por Carneiro (1985); Cervantes, Fujita e Rubi (2008); Dal'Evedove (2014); Dal'Evedove e Fujita (2015); Fujita e Gil Leiva (2009); Fujita e Santos (2016); Gil Leiva e Fujita (2012); Guimarães (2004); Kochani, Boccato e Rubi (2012); Lousada et al. (2011); Nunes (2004); Redigolo et al. (2012); Rubi (2008); Rubi, Fujita e Boccato (2012a e 2012b), entre outros. O interesse da comunidade científica da área de Organização e Representação do Conhecimento pela temática decorre, principalmente, da complexidade da atividade de indexação com fins de representação e recuperação da informação, bem como pela relevância e influência deste recurso para a formação e atuação profissional de bibliotecários.

Por delimitar os procedimentos de indexação, contemplando os princípios, métodos e orientações para a condução da atividade com efeitos

\begin{abstract}
A set of eight guiding guidelines for the preparation of indexing policies in Brazilian university libraries is presented, as a result of a verbal-protocol study among a group of indexers from Brazilian university libraries.
\end{abstract}

Keywords: Subject cataloguing. Indexing policies. Verbal protocol. Sociocultural approach. University libraries. Brazil.

na recuperação, a política de indexação interessa ao sistema de informação e seus respectivos sujeitos: profissionais que realizam o tratamento temático de documentos, gestores de sistemas de recuperação da informação e usuários (Dal'Evedove e Fujita, 2012, p. 13). Na prática, as pesquisas na temática centram esforços para o aprofundamento de aspectos teóricos, metodológicos e pedagógicos considerando não apenas o bibliotecário indexador, uma vez que em bibliotecas universitárias, por exemplo, outros atores sociais estão atrelados direta ou indiretamente aos resultados provenientes da elaboração e aplicação deste recurso (Dal'Evedove, 2010).

Dessa forma, as relações humanas atuantes na representação de assunto precisam ser consideradas para que os produtos e serviços informacionais gerados a partir do processo de tratamento temático da informação não sejam abandonados à espontaneidade da subjetividade ou "bom senso" profissional; alheios às necessidades informacionais dos usuários; ou mesmo apartados da literatura especializada. Essa enorme tarefa 
não poderá ser realizada a menos que, sob uma vigência coletiva, os fenômenos, manifestações e entendimentos que cercam este fazer profissional sejam observados a partir da percepção dos atores sociais que compõem esse universo.

Em pesquisa realizada por Dal'Evedove (2014) intitulada Tratamento temático da informação em abordagem sociocognitiva: diretrizes para elaboração de política de indexação em bibliotecas universitárias (1), a autora centrou esforços para os desafios da política de indexação frente à diversidade cultural. Tomou-se como base a concepção de que a política de indexação precisa refletir o conjunto de ideias, valorações, atitudes e conceitos peculiares dos atores sociais que compõem o Tratamento Temático da Informação no campo dos acontecimentos discursivos, para que suas diretrizes sejam coerentes com os princípios teóricos e metodológicos da área de Organização e Representação do Conhecimento, com a prática cotidiana da profissão e, sobretudo, com a realidade específica do contexto de bibliotecas universitárias que disponibilizam seus produtos e serviços informacionais por meio de catálogos coletivos online. Nessa direção, a proposta foi contribuir com diretrizes de políticas de indexação elaboradas mediante investigação da vertente humana do processo em contextos de bibliotecas universitárias.

Esta ideia ampara-se na necessidade de primar pela garantia cultural às informações construídas como prática social em domínios informacionais específicos (Beghtol, 2002). Com efeito, passase a considerar o contexto sociocultural que envolve o processo de tratamento temático da informação em razão do processo de conhecimento individual ser socialmente condicionado (Fujita, 2007).

Na referida pesquisa o Tratamento Temático da Informação foi delineado no campo dos acontecimentos discursivos, quais sejam: a) fundamentos teóricos e metodológicos do corpo de docentes da área de Organização e Representação do Conhecimento; b) contexto sociocognitivo do bibliotecário indexador; e c) características e princípios culturais dos usuários. Buscou-se, para tanto, investigar as diferentes vertentes que compõem o processo em abordagem sociocultural, delimitadas em: vertente científica composta pelos docentes que ministram disciplinas relacionadas à área de Organização e Representação do Conhecimento no âmbito do Tratamento Temático da Informação; vertente profissional constituída pelos profissionais bibliotecários indexadores que atuam em contexto de bibliotecas universitárias; e vertente de uso formada pela comunidade usuária.
Considerando-se como fatores o cenário que envolve a pesquisa nas Ciências Sociais e, especificamente, a busca por resultados proveitosos, a linha de raciocínio adotada foi a do método fenomenológico. Enquanto um modelo compreensivo em detrimento da mera explicação de fenômenos, o método em destaque torna "[...] explícita a estrutura e o significado implícito da experiência humana" (Sanders, 1982, p. 353). O ponto chave da Fenomenologia é compreender a essência dos fenômenos em análise a partir dos significados que as experiências vividas têm para os sujeitos; considerando sua individualidade e suas relações sociais estabelecidas e experienciadas em contextos diversos.

A primeira parte do estudo consistiu na elaboração e aplicação de três questionários eletrônicos, cada qual direcionado para um grupo pesquisado, a fim de identificar: a) o conhecimento e concepção dos docentes sobre os princípios teóricos e metodológicos da política de indexação; b) a prática cotidiana da comunidade profissional atuante no processo de tratamento temático da informação e a questão da política de indexação no contexto das bibliotecas universitárias; e c) a percepção dos usuários quanto da precisão dos produtos informacionais resultantes da recuperação da informação realizada nos catálogos coletivos online. $O$ teor das questões em cada um dos questionários pode ser consultado em Dal'Evedove (2014). Do total dos questionários respondidos, obteve-se um grupo social composto por doze docentes, quatro profissionais e cinquenta usuários. Isto quer dizer que $29,3 \%$ do total dos sujeitos identificados na vertente científica participaram da pesquisa, sendo $13,8 \%$ na vertente profissional e $67,6 \%$ na vertente de uso. O número de atores sociais identificados foi 144 , sendo o total de sujeitos participantes 66 . O baixo retorno dos questionários enviados aos docentes foi justificado por apenas dezesseis sujeitos participantes que alegaram falta de tempo e excesso de trabalho. Os bibliotecários indexadores que não responderam ao questionário não se manifestaram.

A análise conjunta e comparativa dos questionários viabilizou a obtenção de resultados que refletem a realidade do processo na perspectiva das diferentes vertentes investigadas. Os resultados obtidos contribuíram diretamente para: a) conhecer o universo discursivo-reflexivo da política de indexação na perspectiva dos atores sociais testados e, de modo concreto, distinguir os pontos favoráveis e adequados para o contexto de bibliotecas universitárias; e b) incorporar elementos de cada uma das vertentes investigadas e de seus respectivos atores sociais na composição de diretrizes para a definição de políticas de indexação para o contexto de bibliotecas universitárias. 
Com base nestes resultados, foram traçados novos elementos de política de indexação para bibliotecas universitárias. Como forma de verificar a pertinência e exequibilidade de tais indicações pela perspectiva da prática profissional, utilizouse no segundo momento da pesquisa o Protocolo Verbal em Grupo. A aplicação desta técnica introspectiva de coleta de dados serviu para identificar as opiniões, impressões e conhecimentos dos sujeitos participantes sobre os elementos de política de indexação estabelecidos por meio da análise dos questionários.

Diante do exposto, a proposta neste artigo é apresentar os resultados advindos com a aplicação do Protocolo Verbal em Grupo com profissionais bibliotecários indexadores, a fim de expor as diretrizes para definição de política de indexação obtidas ao término da pesquisa, de modo a divulgá-las para a comunidade científica e profissional.

\section{Procedimentos metodológicos}

A utilização do Protocolo Verbal em Grupo como técnica introspectiva para coleta de dados serviu para verificar junto à sociedade profissional se os elementos estabelecidos com base nos resultados dos questionários eram compatíveis com a realidade dos contextos de bibliotecas universitárias e com a prática cotidiana do bibliotecário indexador, com vistas a sua adequação.

Reconhece-se, portanto, a importância do sujeito no processo de construção do conhecimento, visto que a realidade é construída socialmente e entendida como o percebido, interpretado e/ou comunicado. A importância do levantamento destas manifestações reside no fato de que os bibliotecários indexadores precisam estar confortáveis diante destas diretrizes para que venham a utilizá-las no momento da elaboração de uma política de indexação específica para a biblioteca universitária em que atuam. Sendo assim, a escolha do Protocolo Verbal em Grupo justifica-se em decorrência de que (Rubi, 2008, p. 18)

[...] quem conhece a política de indexação é o profissional que a faz e somente ele poderá iniciar e dar continuidade ao processo de construção de novos conhecimentos sobre a indexação e, conseqüentemente, sobre sua política, dentro do sistema de informação.

De modo geral, nesta modalidade de Protocolo Verbal os sujeitos participantes verbalizam o conhecimento processual individual para desvendar determinada atividade de leitura, alternandose o conhecimento prévio com a leitura e discussão do texto apresentado de modo aleatório (Nardi, 1999).
Para que as medidas tomadas para a aplicação do Protocolo Verbal em Grupo não fossem avulsas, foram adotados os procedimentos metodológicos elaborados por Nardi (1999), sendo exposto uma contextualização geral sobre as etapas realizadas em cada tópico dos procedimentos anteriores, durante e posteriores à aplicação, conforme segue:

I. Procedimentos anteriores às sessões de aplicação da coleta de dados:

- Definição do universo da pesquisa: A aplicação da técnica ocorreu com três bibliotecários indexadores atuantes na Biblioteca do Instituto de Matemática, Estatística e Computação Científica da Universidade Estadual de Campinas - UNICAMP (área de exatas).

Proposta de diretrizes de política de indexação para bibliotecas universitárias

- As características e objetivos institucionais deverão đ్. ser claramente identificados, servindo de orientação para a definição e cumprimento dos demais pontos da política de indexação.

¿ Cada biblioteca universitária deverá estabelecer

$\because$ orientações de conduta ética por meio das quais

\& os profissionais bibliotecários atuantes no tratamento

$\perp$ temático da informação deverão se pautar.

Realizar um estudo sobre a cultura organizacional da biblioteca universitária que seja coerente com a demanda da comunidade usuária.

Prever um estudo de usuário que contemple questões relacionadas ao funcionamento do processo de busca nos sistemas de recuperação da informação, a fim de se conhecer as formas de uso e significação da linguagem pela comunidade usuária.

Delimitar com precisão o nível de abrangência que a indexação será realizada. Recomenda-se que os níveis de análise de assunto sejam encaminhados a partir da concepção orientada ao usuário, na qual o bibliotecário leva em consideração o conhecimento especializado da comunidade usuária sobre os assuntos para realizar a representação conceitual do documento.

® Realizar a representação do conteúdo informativo

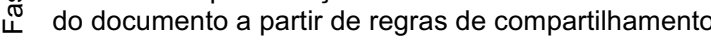
que preservem a garantia cultural, epistêmica e ética da informação.

Adequar os assuntos do documento no momento da representação conceitual de acordo com as características da comunidade usuária.

Prever a criação de diferentes representações do mesmo documento como forma de amparar usuários inseridos em domínios de conhecimento específicos. Recomenda-se que o catálogo da biblioteca ofereça produtos com valor agregado como forma de demonstrar valorização e reconhecimento da importância de seus usuários no provimento de informações.

Tabela I. Texto utilizado na aplicação do Protocolo Verbal em Grupo (Dal'Evedove, 2014) 
- Seleção do texto-base: O material discutido pelos sujeitos de pesquisa foi elaborado mediante a análise comparativa dos resultados provenientes dos questionários aplicados com docentes, profissionais e usuários que permitiram a delimitação de alguns elementos de política de indexação para o contexto de bibliotecas universitárias (Tabela I).

- Definição da tarefa: Ocorreu a recepção dos sujeitos participantes pela pesquisadora para uma apresentação formal entre as partes; e conversa informal entre a pesquisadora com os sujeitos participantes para expor os objetivos e relevância da pesquisa, bem como para realizar a familiarização dos sujeitos com a técnica.

II. Procedimentos durante a coleta de dados:

- Gravação do "Pensar Alto" do grupo de sujeitos participantes durante a discussão do Texto-Base: A gravação do "Pensar Alto" dos sujeitos durante a discussão do material ocorreu por meio de um gravador digital.

- Entrevista retrospectiva (optativa): O intuito desta manobra foi esclarecer dúvidas sobrepostas durante a execução da atividade em análise e incitar discussões de tópicos pouco explorados ou não abordados pelo grupo durante a discussão principal.

III. Procedimentos após o término das sessões de coleta de dados:

- Transcrição literal das gravações das falas dos sujeitos participantes: Realizou-se a transcrição dos dados, na íntegra, com a identificação das fontes individuais de cada sujeito participante. Para uma melhor exposição, todas as falas individuais foram numeradas em turnos, o que facilitou a análise dos dados e manteve a natureza contínua da interação entre os sujeitos de pesquisa. Na parte prática das transcrições, utilizou-se o Express Scribe Transcription Software que, por ser um software destinado para auxiliar os digitadores na transcrição de textos falados para escritos, contribuiu para melhorar a confiança e validade das transcrições, não havendo perda de dados.

- Leitura detalhada dos dados em busca de fenômenos significativos e recorrentes para a construção das categorias de análise: Ocorreu uma leitura detalhada das transcrições do protocolo verbal por parte da pesquisadora na busca por aspectos relevantes e fenômenos significativos que permitissem a construção das categorias para análise dos dados coletados. Esta etapa foi baseada na leitura para observação.
- Construção das categorias de análise: A construção das categorias de análise pautouse nos referenciais teóricos abordados e discutidos em Dal'Evedove (2014) e nos depoimentos dos sujeitos participantes.

- Retorno aos dados para retirar trechos da discussão que exemplifiquem cada categoria de análise: Houve, neste momento, uma releitura das transcrições das coletas de dados para a retirada de trechos da discussão que melhor exemplificassem cada fenômeno (objeto de estudo) abordado nas categorias de análise e seus tópicos referenciais.

- Análise dos dados: Concluídas as etapas anteriores, a análise dos dados foi baseada nas declarações realizadas pelos sujeitos de pesquisa em relação aos elementos contidos nas diretrizes apresentadas como produto da discussão social. A análise qualitativa dos dados obtidos ficou a cargo da Análise de Conteúdo (Bardin, 2009) como forma de obter a fruição da realidade dos dados coletados mediante a concepção dos atores sociais testados.

\section{Apresentação e discussão dos resultados}

Os elementos de política de indexação discutidos foram elaborados em Dal'Evedove (2014) considerando-se, para tanto, as indicações teóricometodológicas presentes na literatura especializada da área de Organização e Representação do Conhecimento e dos resultados obtidos por meio dos questionários. Os elementos foram apresentados adotando-se as duas primeiras fases da elaboração de política de indexação: preparação e desenvolvimento; uma vez que a avaliação enquanto terceira e última etapa é o momento em que o modelo de política de indexação será discutido pela equipe da biblioteca universitária para indicação de ajustes e melhorias e, também, para completar a proposta de diretrizes (Rubi, 2008).

Dentre todas as falas transcritas do protocolo verbal, são utilizadas aquelas que melhor explicitam e/ou exemplificam os temários abordados nas respectivas categorias de análise. Os trechos significativos de cada categoria estão sublinhados, sendo dispostos de maneira complementar com uma síntese analítica acerca dos exemplos apresentados, com destaque aos aspectos referentes à política de indexação. A ênfase na análise dos dados coletados foi direcionada na tentativa de identificar as opiniões, impressões, concepções e comportamentos pessoais e coletivos dos profissionais bibliotecários investigados acerca dos elementos exploradas durante a discussão grupal. 


\subsection{Elementos de política de indexação} do ponto de vista profissional

A primeira etapa é o momento em que, depois de verificadas todas as condições de preparação para o desenvolvimento da política de indexação, toda e qualquer decisão e/ou diretriz a ser estabelecida deve corresponder aos objetivos e à filosofia da biblioteca, da organização na qual está inserida e dos usuários atendidos (RUBI, 2008). Em sintonia com tal indicação, o primeiro item apresentado para uma avaliação pontual dos bibliotecários indexadores comporta questões de gestão, cultura organizacional e comportamento profissional, a saber:

\subsubsection{As características e os objetivos institucionais deverão ser claramente identificados, servindo de orientação para a definição e cumprimento dos demais pontos da política de indexação}

Os sujeitos dedicaram grande parte da discussão sobre a importância desta fase da política de indexação, o que demonstra uma preocupação pelo estabelecimento de um recurso que considere o contexto de informação, suas características e particularidades. Na ótica dos sujeitos, torna-se de grande relevância que as características e os objetivos da biblioteca universitária sejam considerados na política de indexação, sendo preciso, para tanto, conhecer o usuário para que o bibliotecário indexador tenha condições de elaborar um recurso que seja coerente e passível de aplicabilidade no âmbito da biblioteca universitária. Seus discursos indicam que a definição precisa das características e objetivos institucionais servirão de orientação para o estabelecimento e cumprimento dos demais pontos da política de indexação. O posicionamento dos sujeitos participantes reafirma o pensamento de que a política de indexação deve ser compreendida como uma decisão administrativa por parte das bibliotecas universitárias, sendo representada por meio de uma filosofia que reflita os objetivos da instituição.

[19 Sujeito 2] Agora, eu acho que a pessoa mais importante para desenvolver uma política de indexação são os usuários e a instituição como um todo. Eu acho que tem que levar em consideração qual é a função dela, qual são os objetivos, o público que vai atender o nível de especificidade que tem que ter

Além disso, os sujeitos indicam que a política de indexação deve estar regulamentada e publicada. A literatura especializada da área recomenda esta prática e defende a necessidade do registro formal da política de indexação em manuais de indexação (Rubi, 2008), como forma de salvaguardar a sua continuidade, avaliação e aperfeiçoamento ao longo do tempo e, sobretudo, para que todos os profissionais envolvidos com a atividade tenham conhecimento claro acerca "[...] das decisões tomadas, suas razões e seu contexto" (Guimarães, 2000, p. 56).

Esta confluência de ideias atesta que o momento que antecede a política de indexação é crucial para cada contexto de informação identificar com precisão todos os aspectos a serem considerados nestas diretrizes, ação que viabiliza o cumprimento de tais indicações no cotidiano da atividade. Nunes (2004, p. 57) esclarece que sendo a política de indexação um documento específico de cada biblioteca universitária, "[...] há que se admitir diferentes gradações dessa política. Isso é absolutamente esperado. O que não é esperado é a ausência completa de políticas formalmente enunciadas [...]”. Na ótica dos participantes a publicação da política de indexação possibilita que outras instituições sejam beneficiadas, como forma de divulgar o trabalho realizado pela instituição, contribuindo com diálogos e trocas de conhecimentos entre os bibliotecários indexadores no cumprimento de suas ações profissionais.

[18 Sujeito 2] É importante ter um documento que comprove e também você divulgar a forma que você faz a catalogação, porque você vai unir esforços para ver o que outra instituição está fazendo, assim trazer melhorias para a política e divulgar o que você faz, trocar ideias entre pares, com bibliotecas da mesma área.

Na prática, consideram que o ato de regulamentar e publicar a política de indexação contribui para que esforços sejam minimizados e a política de indexação seja aperfeiçoada.

\subsubsection{Cada biblioteca universitária deverá estabelecer orientações de conduta ética por meio das quais os profissionais bibliotecários atuantes no tratamento temático da informação deverão se pautar}

$O$ enunciado foi bem aceito pelos sujeitos participantes ao demonstrarem a relevância da inclusão desta questão na política de indexação, como forma de contribuir para uma possível padronização e conduta profissional no tratamento temático da informação. Sobre isto, cabe reafirmar que o bibliotecário indexador realiza o processo em um contexto cultural e ideológico e, por isso, suas crenças pessoais interferem na representação do conhecimento (Pinho, 2010). Dessa forma, prever na política de indexação questões de orientação e conduta ética é contribuir para que a atuação profissional seja coerente com os objetivos institucionais. Para os sujeitos participantes, tal indicação permite que os bibliotecários indexadores tenham uma visão mais adequada da realidade profissional e reflitam sobre 
suas ações na indexação. No geral, consideram que diretrizes que tenham essa conotação sejam necessárias na política de indexação por contribuírem para uma mudança de ações e postura profissional frente aos desafios que lhes são colocados todos os dias na prática cotidiana da profissão.

[35 Sujeito 1] Agora nesse ponto: cada biblioteca universitária deverá estabelecer orientações de conduta ética por meio das quais os profissionais bibliotecários atuantes no tratamento temático da informação deverão se pautar, isso aqui também é importantíssimo, porque se ninguém seguir 0 mesmo padrão e falar a mesma linguagem vai ficar sem padrão.

\subsubsection{Realizar um estudo sobre a cultura organizacional da biblioteca universitária que seja coerente com a demanda da comunidade usuária}

Esta indicação foi considerada de extrema relevância pelos sujeitos participantes como forma de identificar o contexto em que a biblioteca universitária está inserida e, consequentemente, definir com maior precisão a função da biblioteca e os objetivos a serem assumidos por ela na atribuição de suas atividades. É notória a postura reflexiva dos sujeitos sobre a importância de a cultura organizacional ser trabalhada em uma política de indexação direcionada para bibliotecas universitárias, sendo estas "imbuídas da responsabilidade de mapear e atender às necessidades e intenções de seus usuários" (Carvalho, 2004, p. 169) com rigor e excelência. Ademais, é oportuno ressaltar que a política de indexação requer avaliações contínuas, especificamente no que tange à linguagem documental quanto do seu "[...] desempenho durante a busca por assunto na recuperação da informação que possa orientar seu aprimoramento e seu uso no processo de representação para indexação documentária" (Boccato, 2009, p. 236).

Para os sujeitos participantes, o estudo da cultura organizacional viabiliza a identificação dos elementos essenciais que fundamentam a política de indexação na biblioteca universitária, diante de suas particularidades e realidade próprias. Afirmam ainda que, assim como a universidade preserva a sua cultura, a biblioteca universitária também precisa preservar a sua cultura organizacional e estender essa preocupação no momento do estabelecimento de sua política de indexação, resgatando o histórico da instituição para se delimitar com maior propriedade as iniciativas que deram certo e as que sofreram mudanças ao longo dos anos.

[31 Sujeito 1] Mas assim, é importante na política também resgatar o histórico, o passado porque tem gente nova que não conhece as tentativas que deram erradas e as que deram certo, então é importantíssimo documentar o histórico da atividade, da instituição para resgatar a cultura da organização porque é ela que vai definir o caminho que a instituição tem que direcionar para elaborar a política.

[35 Sujeito 1] Agora, realizar um estudo sobre a cultura organizacional da biblioteca universitária que seja coerente com a demanda da comunidade usuária também é algo muito importante.

[36 Sujeito 2] A cultura é quem fornece os elementos essenciais que darão um norte, que fundamenta qualquer política para uma biblioteca no ambiente da universidade, qual o contexto em que a biblioteca está inserida.

\subsubsection{Prever um estudo de usuário que contemple questões relacionadas ao funcionamento do processo de busca nos sistemas de recuperação da informação, a fim de se conhecer as formas de uso e significação da linguagem pela comunidade usuária}

Para os bibliotecários indexadores é preciso conhecer as opiniões e interesses dos usuários para definir os critérios a serem empregados no estabelecimento da política de indexação. Essa postura compromissada por parte dos sujeitos indica que a presença do usuário parece ser vista como essencial quando se considera a elaboração de política de indexação. Outra questão é de que o bibliotecário precisa conhecer a área de especialização da biblioteca universitária para poder compreender a linguagem adotada pelo usuário.

No geral, verifica-se que os sujeitos participantes são favoráveis de que os sistemas de informação sejam planejados de modo a respeitar as particularidades de cada biblioteca universitária, de modo a viabilizar a troca de experiências entre usuários e bibliotecários, pois

[...] deve haver um esforço do bibliotecário no que diz respeito à representação adequada do conteúdo do documento. No entanto, isso às vezes não ocorre, cabendo ao usuário, geralmente especialista no assunto, auxiliar o bibliotecário nessa tarefa (Rubi, 2008, p. 156).

Mesmo não sendo especialista em todos os assuntos de que trata, o bibliotecário indexador interage com o documento a partir de linguagens documentais especializadas, considerando a intenção do sistema de informação e a estrutura textual do documento. Neste sentido, os sujeitos participantes entendem que conhecer o processo de busca e as formas de uso e significação da linguagem pelos usuários contribui para que a linguagem documental adotada pelo sistema seja 
atualizada e a representação conceitual corresponda ao assunto designado pelo usuário no momento da busca.

[21 Sujeito 2] Agora, conhecer a área do usuário eu acho que é muito importante, eu acho que todo o bibliotecário deveria conhecer a área que ele trabaIha pelo menos o básico. O bibliotecário precisa ter o conhecimento para poder conversar, ter a mesma linguagem do usuário.

[36 Sujeito 2] Prever um estudo de usuário que contemple questões relacionadas ao funcionamento do processo de busca da informação pela comunidade usuária, a fim de se conhecer as formas de uso e significação da linguagem pelos usuários.

Depois de verificadas todas as condições de preparação para a elaboração da política de indexação, a fase de desenvolvimento é a etapa composta de decisões e diretrizes que deverá corresponder aos objetivos e à filosofia da biblioteca, da organização na qual está inserida e dos usuários atendidos. Neste ponto da discussão, a primeira indicação a ser considerada na elaboração da política de indexação compreende:

\subsubsection{Delimitar com precisão o nível de abrangência que a indexação será realizada}

A preocupação dos sujeitos participantes foi demonstrar situações vivenciadas na prática profissional que atestam a relevância desta delimitação no momento do tratamento temático da informação, considerando, dentre outros fatores, a recuperação no sistema de informação. Cunha (2000, p. 81) esclarece que "a política de indexação seguida pela biblioteca é que irá delinear quais níveis de representação da informação serão adotados em um determinado acervo". No geral, a tendência entre as bibliotecas universitárias é representar o assunto dos documentos no nível mais geral, o que acarreta a recuperação de um grande número de documentos (Rubi, 2008).

Nas diretrizes de política de indexação contidas na literatura especializada, o momento da especificidade é considerado crucial, pois se a precisão não for contemplada, o usuário despenderá de um esforço maior para selecionar o item documental que satisfaça as suas intenções de busca (Rubi, 2008). Diante disso, a política de indexação é o local apropriado para se definir com precisão o nível de especificidade do documento a ser representado na biblioteca universitária.

[38 Sujeito 2] Já na questão do desenvolvimento, quando o texto fala que é preciso delimitar com precisão o nível de abrangência que a indexação será realizada é bem aquilo que eu falei antes, era isso que eu estava querendo dizer para vocês, eu acho que a gente não tem isso aqui, embora nós tenhamos muita coisa que a gente adota e usa na prática, ainda não está definido isso, porque tem gente que mantém termos gerais.

\subsubsection{Realizar a representação do conteúdo informativo do documento a partir de regras de compartilhamento que preservem a garantia cultural, epistêmica e ética da informação}

A postura assumida pelos sujeitos participantes foi favorável com o enunciado. Consideram, portanto, que a garantia cultural, epistêmica e ética da informação são questões que merecem atenção na política de indexação. Apesar de ao longo da discussão social a cultura no âmbito do contexto de bibliotecas universitárias ter sido uma questão bastante abordada, outros pontos do enunciado em destaque não foram amplamente discutidos pelos sujeitos; fato que prejudicou uma análise mais verticalizada sobre a questão da garantia epistêmica e ética da informação na concepção dos atores sociais testados.

[40 Sujeito 2] Nossa, olha aqui, na questão de preservar a garantia cultural é algo muito importante, olha só de novo a questão da cultura, como isso é importante na política de indexação, em qualquer política [...].

\subsubsection{Adequar os assuntos do documento no momento da representação conceitual de acordo com as características da comunidade usuária}

$\mathrm{Na}$ discussão social deste item, os sujeitos participantes reconhecem a importância de serem consideradas as características e preferências da comunidade usuária, especialmente no momento da busca no catálogo da biblioteca. Para os sujeitos, esta indicação deveria ser considerada no momento da indexação, pois o contato com o usuário permite conhecer os termos utilizados e o modo como a busca é realizada no sistema de recuperação da informação. Como resultado, tem-se a possibilidade de adequar os assuntos do documento no momento da representação conceitual de acordo com as características da comunidade usuária. Sobre isto, Boccato (2009, p. 231) alerta que:

O uso adequado da linguagem documentária no processo de representação para indexação está vinculado ao processo de avaliação constante da busca por assunto, proporcionando elementos norteadores para o aperfeiçoamento e a adequação de um sistema de organização do conhecimento que reflita o contexto informacional, cultural e social em que está inserido.

Considerar as características da comunidade usuária na atribuição de termos descritores é estender as possibilidades de recuperação de informações significativas no catálogo da biblioteca universitária, o aque amplia o grau de satisfação 
dos usuários no uso. Os sujeitos reconhecem a valia deste ser um item considerado na política de indexação para bibliotecas universitárias.

[21 Sujeito 1] Deveria ser um item a ser considerado no momento da indexação, mas ela não está formalizada [...]. Às vezes o usuário indica que um ou outro termo não é mais usado, então a gente aproveita esse momento para atualizar.

[20 Sujeito 2] Por isso que é importante o contato com o usuário porque a gente acaba conhecendo como ele pensa, como ele busca, quais os termos que eles utilizam. Assim, você acaba conhecendo a linguagem deles.

[22 Sujeito 2] O catalogador tem que ter essa preocupação de estar voltado para a recuperação da informação quando eu vou preencher os cabeçalhos, eu vou dar a ênfase no assunto principal, tudo para que o aluno não fique entrando em títulos que ele abre o material e não tem nada a ver com a busca dele.

\subsubsection{Prever a criação de diferentes representações do mesmo documento como forma de amparar usuários inseridos em domínios do conhecimento específicos}

Neste item um dos sujeitos participantes foi contrário com a indicação de criar diferentes representações do mesmo documento como forma de amparar usuários que possuem necessidades informacionais específicas. No entanto, constatouse nesta pesquisa que a abordagem sociocultural defende que a atividade humana é dotada de um sistema de significação em um dado contexto cultural e social, sendo mediada por instrumentos carregados de significação cultural.

No campo da informação, esses princípios coadunam quando se considera que sua preocupação enquanto ciência é tornar a informação significativa para os que dela necessitam, o que implica uma efetiva preocupação sobre as condições, padrões e regras de uso enquanto fatores que tornam a informação significativa, ou seja, considerar o sujeito e suas relações na coletividade. Segundo Carvalho (2004, p. 38), "na sociedade contemporânea, oferecer serviços e produtos com valor agregado representa uma demonstração de valorização e reconhecimento da importância de seus usuários". Este pensamento foi compartilhado por um dos sujeitos participantes que se mostrou favorável com o enunciado ao informar ser esta uma preocupação prioritária no contexto da biblioteca universitária.

Apesar de não ser objetivo da pesquisa se debruçar sobre as implicações que esta prática pode gerar nas atividades e serviços da biblioteca universitária, é oportuno salientar que esta indicação foi considerada válida pelos demais profissionais investigados. Diante disso, entende-se que tal indicação tem condições de ser examinada no momento da definição de uma política de indexação, pois toda informação inserida no sistema de recuperação de informação deve representar o grupo social para quem ela é destinada, sem desvios ou dissociações.

[56 Sujeito 1] Isso é uma opção ótima, porque se for representar o mesmo documento de diferentes maneiras eu concordo, porque eu acho que é uma prioridade pensar nessa opção.

No geral, os resultados obtidos com a discussão do material elaborado sobre os elementos a serem observados na definição de política de indexação em bibliotecas universitárias foram consistentes e permitem constatar a viabilidade da adoção dessas indicações. Os bibliotecários indexadores refletiram diante dos pontos apresentados e, com exceção do último item da segunda categoria de análise, todos foram favoráveis quanto à adoção dessas indicações para a elaboração e/ou manutenção da política de indexação em e para bibliotecas universitárias. Não houve manifestações sobre a necessidade de reformular alguma das indicações expostas. Apesar do incentivo da pesquisadora, os sujeitos participantes não apontaram nenhuma alteração proeminente a ser realizada nas diretrizes apresentadas na discussão social.

Por um lado, considera-se que a aceitação das diretrizes apresentadas à comunidade profissional imprima uma considerável credibilidade ao material proposto. Contudo, os enunciados foram respondidos por um pequeno grupo de bibliotecários indexadores; resultado que abre precedentes para que alguns dos pontos aqui trabalhados tenham sido observados superficialmente pelos sujeitos participantes. Isto não invalida que as diretrizes sejam consistentes e oportunas de serem assumidas no momento da elaboração e/ou adequação da política de indexação, mas indica que o material elaborado e apresentado nesta pesquisa seja discutido por um número maior de bibliotecários indexadores, como contributo à questão e, também, como forma de identificar os aspectos que podem ser considerados inapropriados em outros contextos.

\section{Diretrizes para elaboração de política de indexação em bibliotecas universitárias}

Ao passo que as diretrizes foram consideradas proveitosas e passíveis de uso por parte da comunidade profissional investigada, tem-se um total de oito diretrizes de orientação que permeiam as fases de preparação e desenvolvimento a serem consideradas na definição de uma política de 
indexação para o contexto de bibliotecas universitárias, quais sejam:

- As características e os objetivos institucionais deverão ser claramente identificados, servindo de orientação para a definição e cumprimento dos demais pontos da política de indexação;

- Cada biblioteca universitária deverá estabelecer orientações de conduta ética por meio das quais os profissionais bibliotecários atuantes no tratamento temático da informação deverão se pautar;

- Realizar um estudo sobre a cultura organizacional da biblioteca universitária que seja coerente com a demanda da comunidade usuária;

- Prever um estudo de usuário que contemple questões relacionadas ao funcionamento do processo de busca da informação, a fim de se conhecer as formas de uso e significação da linguagem pela comunidade usuária;

- Delimitar com precisão o nível de abrangência que a indexação será realizada;

- Realizar a representação do conteúdo informativo do documento a partir de regras de compartilhamento que preservem a garantia cultural, epistêmica e ética da informação;

- Adequar os assuntos do documento no momento da representação conceitual de acordo com as características da comunidade usuária; e

- Prever a criação de diferentes representações do mesmo documento como forma de amparar usuários inseridos em domínios do conhecimento específicos.

A tarefa de propor novas diretrizes de política de indexação decorre em razão das bibliotecas universitárias apresentarem diferentes realidades; isto é, terem objetivos e características próprias. Muitas vezes, o que é adequado para uma biblioteca universitária pode não ser pertinente para outra. Sendo assim, optou-se por seguir a linha de propor diretrizes pensando-as como algo flexível, em que cada biblioteca universitária deve adequar estas indicações de acordo com os objetivos a serem alcançados no cumprimento de suas atividades. Com efeito, ressalta-se que todas as diretrizes aqui apresentadas visam tornar a política de indexação mais coerente quanto à aplicação dos conhecimentos teóricos do processo diante das especificidades da prática cotidiana da profissão realizada em contextos diversificados por domínios de conhecimento especializados.
Diante da carência de estudos que realizem menções ou busquem uma confluência direta entre os atores sociais ativos no estabelecimento, execução e resultado do processo de tratamento temático da informação realizado em contexto de bibliotecas universitárias, esta pesquisa abre caminhos alternativos para se trabalhar com a política de indexação, além de novas diretrizes de orientação para a elaboração e/ou avaliação deste recurso em bibliotecas universitárias brasileiras.

\section{Considerações finais}

A pesquisa se desenvolveu valendo-se da importância da inclusão na política de indexação de elementos que sustentem e amparem a informação construída como prática social, isto é, que, além de promoverem sintonia entre as concepções teóricas e a prática profissional, preservem os valores, crenças e predisposições específicas da comunidade usuária.

O caminho percorrido foi propício por trazer à tona novas diretrizes de política de indexação que, além de contribuírem para que o tratamento temático da informação em contexto de bibliotecas universitárias seja realizado de modo coerente, atrelando os objetivos institucionais aos de sua comunidade usuária, abrem novas possibilidades investigativas de se trabalhar com questões relativas à política de indexação.

Adotou-se o posicionamento de que a sistematização de diretrizes de política de indexação em e para bibliotecas universitárias deve ser conduzida com base nas indicações que apontam para a necessidade de se considerar o usuário como sujeito inserido em um domínio do conhecimento. Então, significa dizer que para ser adequadamente assimilada é preciso admitir que a informação seja situacional e, portanto, os produtos e serviços informacionais gerados nas atividades de organização e representação da informação precisam contemplar esta característica. Logo, a cultura dos usuários precisa ser refletida nos produtos e serviços informacionais gerados, considerando-os como sujeitos coletivos inseridos em um contexto cultural e social de atividade.

Diante desta nova configuração, buscou-se ao longo da pesquisa apontar que a política de indexação acentua de forma regulamentada que, em se tratando da representação do conteúdo do documento, o interesse da comunidade da biblioteca universitária figura acima de outros. Mais do que isso, quando bem delimitada, a política de indexação contribui para que a representação do documento torne a informação significativa para o usuário ao estabelecer passos de orientação para que a informação seja vinculada ao contexto 
cultural e social em que ela é tratada, organizada e socializada.

Dentre outros aspectos, o conjunto de diretrizes de orientação para a definição de política de indexação apresentado aqui propicia uma relação mais harmoniosa entre o 'saber' e o 'fazer' no que tange à prática do processo, como forma de salvaguardar o objetivo da biblioteca universitária enquanto instituição direcionada à socialização do conhecimento - atendimento efetivo das necessidades informacionais de seus usuários. Portanto, defende-se que tais diretrizes devam ser assumidas no momento da elaboração e/ou reformulação da política de indexação para o contexto de bibliotecas universitárias que possuam sistemas de recuperação de informação automatizados.

O encaminhamento de pesquisas que busquem novas reflexões sobre as questões que envolvem a política de indexação em abordagem sociocultural é um direcionamento eficaz para se estabelecer, com um mínimo de suporte necessário, diretrizes que preservem as características e particularidades dos sistemas de informação. Os resultados apresentados devem servir como suporte e direcionamento para novas pesquisas avancem nas reflexões aqui encabeçadas e propiciem formas inovadoras de se pensar a política de indexação para biblioteca universitária enquanto contexto social de natureza complexa e dinâmica.

Reconhecendo a responsabilidade que cerca toda e qualquer discussão sobre política de indexação, não há nesta pesquisa a pretensão de esgotar a questão, nem seria tal empreendimento possível, pois esta prática contempla o acompanhamento de fenômenos que se revestem de aspectos sociais, cognitivos e culturais - o fazer profissional, o sistema de informação e o usuário. Todavia, admite-se a necessidade de novas alternativas de produção do conhecimento sobre política de indexação que sejam construídas coletivamente, para que este seja um recurso funcional. Por fim, espera-se que os resultados expostos sirvam aos propósitos práticos da comunidade profissional atuante em bibliotecas universitárias.

\section{Notas}

(1) Pesquisa de doutorado realizada no Programa de PósGraduação em Ciência da Informação da Universidade Estadual Paulista (UNESP/Campus de Marília, Brasil) defendida em 2014

\section{Referências}

Bardin, L. (2009). Análise de Conteúdo. Lisboa, Portugal; Edições 70, LDA, 2009.
Beghtol, C. (2002). A proposed ethical warrant for global knowledge representation and organization systems. // Journal of Documentation (London). 58:5 (2002) 507-532.

Boccato, V. R. C. (2009). Avaliação do uso de linguagem documentária em catálogos coletivos de bibliotecas universitárias: um estudo sociocognitivo com protocolo verbal. 299 f. Tese (Doutorado em Ciência da Informação) - Faculdade de Filosofia e Ciências, Universidade Estadual Paulista, Marília, 2009.

Carneiro, M. V. (1985). Diretrizes para uma política de indexação. // Revista da Escola de Biblioteconomia da UFMG, Belo Horizonte. 14:2 (set. 1985) 221-241.

Carvalho, I. C. L. (2004). A socialização do conhecimento no espaço das bibliotecas universitárias. Rio de Janeiro: Interciência, 2004.

Cervantes, B. M. N.; Fujita, M. S. L.; Rubi, M. P. (2008). Terminologias em política de indexação. // Ibersid. (2008) 211-221.

Cunha, M. B. da. (2000). Construindo o futuro: a biblioteca universitária brasileira em 2010. // Ciência da Informação (Brasília). 29:1 (jan./abr. 2000) 71-89.

Dal'Evedove, P. R. (2010). A perspectiva sociocognitiva no tratamento temático da informação em Bibliotecas universitárias: aspectos inerentes da percepção profissional. 301 f. Dissertação (Mestrado em Ciência da Informação) - Faculdade de Filosofia e Ciências, Universidade Estadual Paulista, Marília, 2010.

Dal'Evedove, P. R. (2014). O tratamento temático da informação em abordagem sociocultural: diretrizes de política de indexação em bibliotecas universitárias. $266 \mathrm{f}$. Tese (Doutorado em Ciência da Informação) - Faculdade de Filosofia e Ciências, Universidade Estadual Paulista, Marília. 2014.

Dal'Evedove, P. R.; Fujita, M. S. L. (2015). A pesquisa sobre indexação no Brasil: avanços e desafios. // Scire. 17:2 (jul.-dic. 2015) 49-56.

Fujita, M. S. L.; Gil Leiva, I. (2009). Política de indización en latinoamerica. // Ibersid. (2009) 155-162.

Fujita, M. S. L.; Santos, L. P. (2016). Política de indexação em bibliotecas universitárias: estudo diagnóstico e analítico com pesquisa participante. // Transinformação. 28:1 (jan./abr 2016) 59-76.

Gil Leiva, I.; Fujita, M. S. L. (orgs.) (2012). Política de indexação. São Paulo: Cultura Acadêmica; Oficina Universitária. 2012.

Guimarães, J. A. C. (2004). As políticas de indexação como elementos para a gestão do conhecimento nas organizações. // Vidotti, S. A. B. G. (Org.). Tecnologia e conteúdos informacionais. São Paulo: Polis, 2004. 43-52.

Guimarães, J. A. C. (2000). Políticas de análisis y representación de contenido para la gestión del conocimiento en las organizaciones. // Scire (Zaragoza). 6:2 (jul./dic. 2000) 48-58.

Kochani, A. P.; Boccato, V. R. C.; Rubi, M. P. (2012). Política de indexação para clippings: otimização do tratamento temático em coordenadorias de comunicação social brasileiras. Revista Interamericana de Bibliotecología. 35:3 (set.-dic 2012) 257-273.

Lousada, M. et. al. (2011). Políticas de indexação no âmbito da gestão do conhecimento organizacional. // Informação \& sociedade. 21:1 (2011) 191-202.

Nardi, M. I. (1999). A metáfora e a prática de leitura como evento social: instrumentos do pensar a Biblioteconomia do futuro. $272 \mathrm{f}$. Tese (Doutorado em Linguística Aplicada e Estudos da Linguagem) - Pontifícia Universidade Católica, São Paulo, 1999.

Nunes, C. O. (2004). Algumas considerações acerca da ausência de políticas de indexação em bibliotecas brasileiras. // Biblos (Rio Grande do Sul). 16 (2004) 55-61. 
Pinho, F. A. (2010). Aspectos éticos em representação do conhecimento em temáticas relativas à homossexualidade masculina: uma análise da precisão em linguagens de indexação brasileiras. $149 \mathrm{f}$. Tese (Doutorado em Ciência da Informação) - Faculdade de Filosofia e Ciências, Universidade Estadual Paulista, Marília, 2010.

Redigolo, F. M. et. al. (2012). Elementos de política de indización para bibliotecas universitarias del área médica. // Scire (Zaragoza). 18 (2012) 75-86.

Rubi, M. P.; Fujita, M. S. L.; Boccato, V. R. C. (2012a). Del conocimiento tácito al explicito: elaboración de un manual de política de indización en bibliotecas universitarias. // Scire (Zaragoza). 18:2 (2012a), 67-74.

Rubi, M. P.; Fujita, M. S. L.; Boccato, V. R. C. (2012b). Elaboração do manual de política de indexação na formação continuada do catalogador. // Gil Leiva, Isidoro; Fujita, Mariângela Spotti Lopes (Org.). Política de indexação. São Paulo: Cultura Acadêmica, 2012b. 217-227.

Rubi, M. P. (2008). Política de indexação para construção de catálogos coletivos em bibliotecas universitárias. $169 \mathrm{f}$. Tese (Doutorado em Ciência da Informação) - Faculdade de Filosofia e Ciências, Universidade Estadual Paulista, Marília. 2008.

Sanders, P. (1982). Phenomenology: a new way of viewing organizational research. // The Academy of Management Review. 7:3 (1982) 353-360.

Enviado: 2016-04-04. Segunda versión: 2016-06-29. Aceptado: 2016-06-29. 
